\title{
Economic evaluation of robot-assisted radical prostatectomy compared to open radical prostatectomy for prostate cancer treatment in Ontario, Canada
}

Anna Parackal, BSc, MSc ${ }^{1}$; Jean-Eric Tarride, BA, MA, $\mathrm{PhD}^{1,2}$; Feng Xie, BSc, MSc, $\mathrm{PhD}^{1,3}$; Gord Blackhouse, MBA, MSc ${ }^{1,4}$; Jennifer Hoogenes, BS, MS, MSc, PhD ${ }^{5}$; Edward D. Matsumoto, MD, Med ${ }^{5}$; Danielle Hylton, BSc, MSc ${ }^{1,5}$; Wael Hanna, BSc, MBA, MDCM ${ }^{1,5}$; Anthony Adili, PEng, MD ${ }^{5}$; Bobby Shayegan, BSc, MD

${ }^{1}$ Department of Health Research Methods, Evidence \& Impact (HEI), McMaster University, Hamilton, ON, Canada; ${ }^{2}$ McMaster Chair in Health Technology Management, McMaster University, Hamilton, ON, Canada; ${ }^{3}$ Centre for Health Economics and Policy Analysis (CHEPA), McMaster University, Hamilton, ON, Canada; ${ }^{4}$ Programs for Assessment of Technology in Health (PATH), The Research Institute of St. Joseph's Healthcare Hamilton, Hamilton, ON, Canada; ${ }^{5}$ Department of Surgery, McMaster University, Hamilton, ON, Canada

Cite as: Can Urol Assoc J 2020 April 28; Epub ahead of print. http://dx.doi.org/10.5489/cuaj.6376

Published online April 28, 2020

$* * *$

\section{Abstract}

Introduction: Recent health technology assessments (HTAs) of robot-assisted radical prostatectomy (RARP) in Ontario and Alberta, Canada, resulted in opposite recommendations, calling into question whether benefits of RARP offset the upfront investment. Therefore, the study objectives were to conduct a cost-utility analysis from a Canadian public payer perspective to determine the cost-effectiveness of RARP.

Methods: Using a 10-year time horizon, a five-state Markov model was developed to compare RARP to open radical prostatectomy (ORP). Clinical parameters were derived from Canadian observational studies and a recently published systematic review. Costs, resource utilization, and utility values from recent Canadian sources were used to populate the model. Results were presented in terms of increment costs per quality-adjusted life years (QALYs) gained. A probabilistic analysis was conducted, and uncertainty was represented using cost-effectiveness acceptability curves (CEACs). One-way sensitivity analyses were also conducted. Future costs and QALYs were discounted at $1.5 \%$.

Results: Total cost of RARP and ORP were \$47 033 and \$45 332, respectively. Total estimated QALYs were 7.2047 and 7.1385 for RARP and ORP, respectively. The estimated incremental cost-utility ratio (ICUR) was \$25 704 in the base-case analysis. At a willingness-to-pay threshold 
of \$50 000 and \$100 000 per QALY gained, the probability of RARP being cost-effective was 0.65 and 0.85 , respectively. The model was most sensitive to the time horizon.

Conclusions: The results of this analysis suggest that RARP is likely to be cost-effective in this Canadian patient population. The results are consistent with Alberta's HTA recommendation and other economic evaluations, but challenges Ontario’s reimbursement decision.

\section{Introduction}

Prostate cancer $(\mathrm{PCa})$ is the most common non-skin cancer and the third leading cause of cancerrelated death among Canadian men. ${ }^{1}$ In 2017, an estimated 21,300 Canadians were diagnosed with PCa and an estimated 4,100 died from the disease, with the incidence of diagnosis expected to increase to approximately 22,900 in $2019 .{ }^{1}$ However, due to early detection and innovative treatments, the 5-year overall survival rate for $\mathrm{PCa}$ is $95.4 \% .^{2}$ For men diagnosed with clinically localized $\mathrm{PCa}$, radical prostatectomy (RP) and radiotherapy remain as benchmark treatment options. ${ }^{1}$ Both conventional open and robot-assisted techniques are practiced, but adoption of the latter approach has been slow in Canada. While $82 \%$ of RPs performed

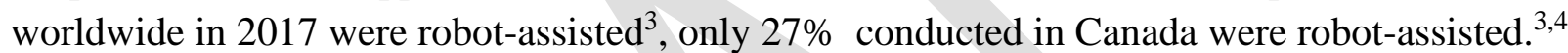

The da Vinci Surgical System (Sunnyvale, CA, USA) is the only system currently available in Canada for robot-assisted radical prostatectomy (RARP). Compared to open RP (ORP), RARP has the benefits of being minimally invasive and offers consistency in functionality and user experience ${ }^{5}$. However, these benefits are associated with incremental costs to acquire, use, and maintain the system. To inform reimbursement decisions around RARP, Health Quality Ontario (HQO) and Alberta Health Services (AHS) independently performed Health Technology Assessments (HTAs) in 2017, reaching different conclusions. When comparing RARP versus ORP, the AHS base case analyses reported an incremental cost of $\$ 44,471$ per quality-adjusted life year (QALY) gained, ${ }^{6}$ while the HQO's was $\$ 5.2$ million per QALY gained. ${ }^{5}$ The AHS model assumptions were consistent with previously published economic evaluations of RARP, ${ }^{7-10}$ whereas the HQO model only considered the costs and benefits associated over a 1-year time horizon as opposed to 10 years in other models. The HQO HTA disregarded the large body of non-randomized studies in favor of the interim results of a randomized controlled trial (RCT) conducted in Australia by Yaxley et al. (2016). ${ }^{11}$ This RCT has received criticism, as the study compared two surgeons: one with 15 years of ORP experience; and the other with 2 years of RARP experience. The outcomes were assessed at 12 weeks, which is too early to be meaningful as acknowledged by the RCT's authors. ${ }^{11,12}$ Consequently, HQO recommended against the reimbursement of RARP, potentially leading to endangerment of medical innovation in Ontario. Therefore, the study objective was to conduct an economic evaluation to re-evaluate RARP relative to ORP for early stage PCa patients in Ontario. 


\section{Methods}

\section{Study overview}

A Markov model was developed to compare the costs and outcomes of treating Ontario patients diagnosed with localized, stage I, or stage II PCa with RARP or ORP. The model considered the probabilities and utilities associated with oncological and functional outcomes over a 10-year time horizon, as well as the corresponding direct medical costs. The analyses were conducted from a public payer perspective. Costs and outcomes beyond one year were discounted at $1.5 \%$.

\section{Model structure}

$\mathrm{RP}$ is considered to be a form of definitive therapy. ${ }^{13}$ While the evidence of no disease is indicative of treatment success, patients are followed over time to identify cancer relapse. Recurrence is measured by the increasing prostate-specific antigen (PSA), which is clinically significant at $>0.2 \mathrm{ng} / \mathrm{ml}^{14}$ Long-term follow-up studies have shown that once biochemical recurrence (BCR) has occurred, patients are at an increased risk of metastasis. ${ }^{15}$ Consistent with the current understanding of the clinical pathway and previous economic evaluations, a 5-state Markov model was constructed with remission, BCR, metastasis, death due to PCa, and all-cause mortality as possible health states (Figure 1). Urinary incontinence (UI) and erectile dysfunction (ED), two potential adverse events (AEs) following treatment, were incorporated in the model and assumed to occur within the first year. The model includes yearly transition periods after RP as derived from the literature.

\section{Clinical inputs and effectiveness}

A targeted literature search identified available clinical evidence to inform the estimates of effectiveness and safety of RARP and ORP. Transition probabilities between health states without RARP (e.g., ORP to BCR, BCR to metastasis) were derived from Canadian data (Table 1). ${ }^{16-21}$ Standard conventions were used to transfer rates presented in the studies to annual probabilities. ${ }^{22}$ All-cause mortality was derived from Canadian life tables. ${ }^{23}$ RARP treatment effectiveness was based on the latest systematic review and meta-analysis of observational comparative studies conducted by Seo et al. (2016). ${ }^{21}$ Based on 14 studies involving 8,259 patients, the authors reported the relative risk (RR) of BCR in patients undergoing RARP versus ORP at 0.71 (95\% CIs: 0.54-0.93). Since the authors analyzed the data according to the definition of PSA failure and to reflect Canadian practices, we used in our model the RR of 0.71 (95\% CIs: 0.61-0.81) associated with 5 studies (1,485 patients) using PSA $>0.2 \mathrm{ng} / \mathrm{mL}$ as the failure point of BCR. ${ }^{21}$ The probability of developing UI or ED after ORP or RARP were also derived from Seo et al. ${ }^{21}$ Probability of developing UI after RP was informed by 11 studies 
(2,510 patients), and the probability of developing ED after RP was informed by 10 studies (2,142 patients).

\section{Measurement and valuation of health}

Aligned with the Canadian Guidelines for the Economic Evaluations of Healthcare Interventions, ${ }^{24}$ QALYs, which combine quality of life with quantity of life, were used as the primary effectiveness measure for this economic evaluation. Utilities and disutilities (e.g., loss of quality of life due to AE ) were obtained from Canadian population-based studies (Table 2). ${ }^{25,26}$ For each yearly model cycle, the proportion of patients in each health state was multiplied by the health state-specific utility value and summed to estimate the cycle-specific number of QALYs. Additionally, in the first cycle, the proportion of patients with AEs were multiplied by AEspecific utility decrement to calculate QALYs lost from the presence of UI or ED. Total QALYs for each treatment arm were estimated by summing QALYs across the time horizon of the model.

\section{Resource use and costs}

As per the Canadian Guidelines for Economic Evaluations, ${ }^{24}$ the analysis was conducted from the perspective of the Ontario Ministry of Health and Long-Term Care (MOHLTC). Therefore, only direct medical costs were included. The capital costs associated with the da Vinci Surgical System were obtained from Minogue Medical, Inc. (Montreal, QC) and were converted from United States to Canadian dollars using an exchange rate of $1 \mathrm{USD}=\$ 1.32 \mathrm{CAD}$ (the average exchange rate from Oct 2018-Feb 2019). These capital costs included the cost of the base XI unit $(\$ 3,689,400)$, dual console $(\$ 924,000)$, accessories required for a typical 4 -arm procedure $(\$ 3,300)$, as well as reusable equipment $(\$ 198,000)$, for a total of $\$ 4,814,700$. However, this is a one-time fee upfront investment with benefits that last over the whole service life of the system, which was assumed to be 10 years in the base case analysis. ${ }^{7}$ In addition to this cost, the da Vinci incurs an annual maintenance fee of $\$ 290,400$. The cost per-patient associated with the robotic system was calculated by dividing the sum of the equivalent annual cost of the robotic system $(\$ 4,814,700$ divided by 10 years $)$ and its annual maintenance cost $(\$ 290,400)$ by the expected number of robot-assisted surgeries per year per robotic unit. In the absence of recent published data, it was assumed that the robot would be used for 400 surgeries per year based on the experience of our institution (i.e. St Joseph's Health Care Hamilton, SJHH) where the Da Vinci robot was used in 2019 for 275 prostatectomies, 30 nephrectomies, and approximately 95 thoracic surgeries (note that the Da Vinci robot is not used for of hysterectomies at SJHH). This resulted in a per surgery robot cost of $\$ 1,930$ per patient for RARP over a 10-year time horizon (i.e. $[\$ 4,814,700 / 10+\$ 290,400] / 400)$. While we believe this volume of surgeries is fairly typical of an academic center in Canada, we recognize that every academic center will have different case mixes. To reflect this uncertainty, we conducted sensitivity analysis using volume of 350 
(low utilization) and 500 (high utilization) cases per year. Uncertainties around device lifespan (using 5 years instead of 10 years in the calculations), and capital cost (assuming the government will not have to pay for the da Vinci system) were explored in sensitivity analysis.

Table 3 presents the costs associated with RARP $(\$ 17,019)$ and $\operatorname{ORP}(\$ 13,361)$ when taking into account the cost of disposables, operating room time, recovery room time, length of stay, surgeon fees, anesthesia, blood transfusion rate, and readmission rate, which were derived from a recent Ontario retrospective study of 1,606 RPs ( 840 robotic and 766 open). ${ }^{27}$ Following treatment, the annual cost associated with remission $(\$ 3,084)$, recurrence $(\$ 9,435)$, and metastasis $(\$ 17,296)$ were derived from an Ontario prostate-specific costing study involving 826 patients. ${ }^{28}$ These costs were attributable to diagnostic tests, family practitioner visits, specialist visits, non-diagnostic medical procedures inpatient stays, same-day surgery, and emergency room visits, outpatient medications, home care/complex care/long term care and radiation therapy. The details are presented in Table 4 by component. Because ED medications are not reimbursed by the Ontario Drug Benefit formulary, no costs were assigned to patients with ED. The proportion of individuals with UI who receive an artificial urinary sphincter (AUS) or a urethral sling after ORP was based on the study by Nam et $\mathrm{al}^{29}$ which showed that amongst all post-ORP patients in Ontario, $2.8 \%$ received AUS while $1.1 \%$ received a urethral sling. These proportions were assumed to be $1.9 \%$ and $0.7 \%$ for RARP, respectively, based on the difference of UI rate between open $(12 \%)$ and robotic ( $8 \%$ ) prostatectomy. The costs of AUS and urethral sling were estimated by multiplying the proportion of patients with AUS or urethral sling by the unit cost associated with its treatment, which were $\$ 14,690$ and $\$ 5,012$ respectively. ${ }^{5}$

Patients in the first year of the Markov cycle incurred direct medical costs associated with the different health states, AE treatments, and RP procedure. In subsequent years, only the costs associated with the different health states were included. Total costs for each treatment arm were estimated by aggregating the cycle-specific costs over the time horizon of the model. All costs were inflated, as necessary, to 2019 Canadian dollars (\$CAD) using the health care component of Canada's annual Consumer Price Index (CPI) computed by Statistics Canada. ${ }^{30}$

\section{Methods of economic analysis}

As per the Canadian Guidelines on Economic Evaluations, ${ }^{24}$ a cost-utility analysis was conducted to compare the costs and QALYs associated with RARP and ORP from a public payer perspective. Consistent with previous economic evaluations of RARP, ${ }^{6-10}$ the reference case analysis was conducted over a 10-year time horizon. Costs and QALYs that occur beyond one year were discounted to present values at a rate of $1.5 \%$ per year in the base case.

In the reference case, expected values of costs and QALYs were derived through probabilistic analysis using Monte Carlo simulation techniques as per the Canadian Guidelines for Economic Evaluations of Healthcare Technologies ${ }^{24}$ and standard conventions for distributions. ${ }^{22}$ Uncertainty was represented using a cost effectiveness acceptability curve 
(CEAC), which shows the probability of RARP to be cost-effective compared to ORP at different willingness-to-pay (WTP) per unit of effect (e.g., \$50,000 or \$100,000 per QALY gained).

A series of one-way deterministic sensitivity analyses were also conducted to assess the robustness of base case findings in which one parameter value was changed while all the other parameter values were held constant. This includes, for example, varying the annual capital costs of RARP, or changing the life expectancy of the surgical system from 10 to 5 years. The utility associated with remission and BCR varied by $10 \%$, as it was the maximum range by which the respective utilities could be analyzed. Anything beyond $10 \%$ would result in health utility values greater than 1 (i.e., perfect health), surpassing the upper limit. The annual volume robot assisted surgeries was varied from 350 (low volume academic centre) to 500 (high volume academic centre). The reference case analysis assumed that the proportions of patients who suffer from UI or ED experience that $\mathrm{AE}$ for the entire first year. However, in sensitivity analyses, the median time to continence was set to 4 months after the procedure, and the median time to potency was set to 10 months after the procedure as suggested by evidence in the literature. ${ }^{31}$ Since the da Vinci has been so far funded through donation campaigns in Canada, a sensitivity analysis (SA) was completed in which the capital costs of the robot were excluded. Results from the SA of selective model parameters are presented in the form of a tornado diagram (Figure 3).

\section{Results}

\section{Base case}

Over the 10-year time horizon, the incremental cost per QALYs gained when using RARP compared with ORP was estimated to be $\$ 25,704$ in the base case analysis (Table 5). Specifically, total costs were estimated to be $\$ 45,332$ for ORP and $\$ 47,033$ for RARP (incremental costs of \$1,701). The RARP and ORP treatment arms generated 7.2047 and 7.1385 QALYs respectively (incremental QALY of 0.0662). The results of the CEAC indicated that the probability of RARP to be cost-effective compared to ORP was 0.65 and 0.85 at a WTP of $\$ 50,000$ per QALY gained and \$100,000/QALY gained, respectively.

Figure 3 presents the results of the tornado diagram in which the centre line in the diagram represents the deterministic base-case incremental cost-effectiveness ratio (ICER). Among the parameters included in the tornado plot, the ICER was most sensitive to utility of remission and recurrence and the number of procedures per robot per year. Varying the utility of remission by $\pm 10 \%(0.81,0.99)$ can result in an ICER of $\$ 46,947$ or $\$ 17,707$. Varying the assumed annual of procedures per robot per year $(350,500)$ results in an ICER of $\$ 29,795$ or $\$ 19,977$ respectively. In addition, the analysis using a time horizon of 1 year and 5 years yielded ICERs of \$390,965/QALY gained and \$145,301/QALY gained, respectively. Using a device lifespan of 5 years instead of 10 years in the base case analysis yielded an ICER of 
$\$ 43,566 /$ QALY gained. If UI is assumed to resolve at 4 months instead of 1 year the ICER becomes $\$ 26,859$. If the duration of ED is assumed to be 10 months the cost per QALY becomes $\$ 27,753$. Finally, if the MOHLTC does not have to pay for the robotic system, ORP was dominated by RARP.

\section{Discussion}

With an incremental cost of approximately $\$ 25 \mathrm{~K}$ per QALY gained, these results suggest that RARP is cost-effective in Ontario according to the commonly quoted ICER threshold (\$50K/QALY, \$100K/QALY), and should be considered for public reimbursement. Our base case probabilistic analyses, taking into account the uncertainty in the model inputs, indicated that the probability of RARP being cost-effective compared to ORP was 0.65 and 0.85 at a WTP of $\$ 50,000$ and $\$ 100,000 / \mathrm{Q} A L Y$ gained, respectively. The model was most sensitive to change in time horizon and somewhat to the lifespan of the robotic system. For example, using a 5-year time horizon (instead of 10 years in the base case scenario) increased the ICER to $\$ 145 \mathrm{k}$ per QALY gained. However, it can be argued that a 5-year time horizon is too short to evaluate the future costs and benefits associated with RP treatment options. Decreasing the lifespan of the da Vinci Surgical System from 10 years to 5 years increased the ICER to approximately $\$ 45 \mathrm{k}$ per QALY gained. The robot is funded by private donations and not by the MOHLTC. In this case, RARP is superior to ORP (more effective and less costly). The model was less sensitive to changes in other model parameters.

While it is difficult to compare our results to other studies due to differences in study designs, data sources, and/or settings, the calculated ICER of \$25,704 is consistent with the recent economic evaluation conducted by AHS (ICER: \$44,471/QALY gained) and other international economic evaluations of RARP versus ORP (\$24K-\$64K; see Appendix A for a summary), but significantly different from HQO's HTA (\$5.2 million/QALY gained). This was anticipated because of three key reasons. First, the time horizon of our base case model of 10 years is similar to Alberta's timeframe (9 years) and other economic studies conducted in Ireland and the US (e.g., 7 years and life time horizon, respectively), ${ }^{7,8}$ while HQO's model time horizon was 1 year. Secondly, HQO report assumed an annual volume of 200 cases that could be performed with one robotic system (or 4 cases a week assuming that the robot would be used 50 weeks per year) while we assumed in our base case analysis 400 procedures per year based on the experience at our institution (including other surgical use such as nephrectomies and thoracic surgeries). Third, unlike HQO, the clinical and utility parameters were not obtained from the 12week interim analysis of the somewhat criticized Australian RCT, ${ }^{11}$ but rather from observational data. In particular, we used Canadian data to model the natural history of patient candidates for RP and the results of a recently published systematic review and meta-analysis comparing RARP and ORP. ${ }^{21}$ In this sense, our results should be more generalizable to the Ontario context than the HQO model which used Australian interim data. Since the meta- 
analysis by Seo et al. $(2016)^{21}$, the results of a 2-year Swedish non-randomized multicentre trial comparing clinical outcomes of RARP and ORP has been published ${ }^{32}$. However, their data cannot be compared within our analysis, as they set the BCR cut-point at a PSA level of >.25 $\mathrm{mg} / \mathrm{ml}$, which is not reflective of Canadian practice where BCR is determined to be clinically significant at $>.20 \mathrm{ng} / \mathrm{ml}^{14}$

While this study has several strengths (e.g., using Canadian data for costing and natural history of patients), a few limitations should be noted. First and consistent with previous economic studies of RARP, we used non-randomized data to inform our model which is less ideal. However, in the absence of RCT data, non-randomized evidence should be considered for decision making. In our case, the risk of BCR in RARP relative to ORP was derived from a published meta-analysis of observational studies. RCT data is often lacking for non-drug health technologies such as robot assisted surgeries where they are not required for approval and adoption. It should also be noted that due to lack of detailed data, the treatment effect in this economic evaluation is solely based on the risk of BCR. Obtaining direct proportions of remission, risk of metastasis, and risk of death in RARP relative to ORP will provide a better representation of treatment effectiveness and further strengthen the model, but this is left for future research. Moreover, our analysis does not take into consideration the patient perspective such as including out of pocket costs or patient caregiver burden, thereby narrowing its scope. Future economic evaluations of RARP should include a societal perspective for a more comprehensive assessment of cost-effectiveness. Finally, although most of the data are based on Canadian studies, there were still uncertainties related to the input parameters and therefore the model relied on several assumptions. To address this uncertainty, we conducted probabilistic and sensitivity analyses.

\section{Conclusions}

In conclusion, our results based on a de novo model developed to address some of the pitfalls in HQO's HTA (e.g., 1 year time horizon and use of interim data from a RCT conducted in Australia by an experienced ORP surgeon and novice RARP surgeon) suggest that RARP compared to ORP is a cost-effective treatment option for patients with localized PCa in Ontario, Canada. 


\section{References}

1. Canadian Cancer Society.Prostate Cancer Statistics. http://www.cancer.ca/en/cancerinformation/cancer-type/prostate/statistics/?region=on. Accessed November 192019.

2. Tran BX, Nair AV, Kuhle S, Ohinmaa A, Veugelers PJ. Cost analyses of obesity in Canada: scope, quality, and implications. Cost effectiveness and resource allocation : $C / E$. 2013;11(1):3.

3. Finkelstein EA, Allaire BT, DiBonaventura MD, Burgess SM. Direct and indirect costs and potential cost savings of laparoscopic adjustable gastric banding among obese patients with diabetes. Journal of occupational and environmental medicine / American College of Occupational and Environmental Medicine. 2011;53(9):1025-1029.

4. Radical Prostatectomy in Canada, by location of surgery and approach, 2009-2010 to 20142015.Canadian Institute for Health Information. https://www.cihi.ca/sites/default/files/document/quickstat_prostatecancer_en.xlsx. Published 2016. Accessed November 19,2019.

5. Courcoulas AP, Yanovski SZ, Bonds D, et al. Long-term Outcomes of Bariatric Surgery: A National Institutes of Health Symposium. JAMA surgery. 2014;149(12):1323-1329.

6. Alberta Health Services. Robot-Assissted Laparoscopic Prostatectomy (RALP): final report. University of Alberta Health Technology \& Policy Unit 2017. 2017.

7. Health Information and Quality Authority. Health Technology Assessment of Robot-Assisted Surgery in selected Surgical Procedures. Dublin (Ireland): Health Information and Quality Authority 2011:1-218.

8. Cooperberg MR, Ramakrishna NR, Duff SB, et al. Primary treatments for clinically localised prostate cancer: a comprehensive lifetime cost-utility analysis. BJU Int. 2013;111(3):437-450.

9. Hohwu L, Borre M, Ehlers L, Venborg Pedersen K. A short-term cost-effectiveness study comparing robot-assisted laparoscopic and open retropubic radical prostatectomy. J Med Econ. 2011;14(4):403-409.

10. O'Malley SP, Jordan E. Review of a decision by the Medical Services Advisory Committee based on health technology assessment of an emerging technology: the case for remotely assisted radical prostatectomy. Int J Technol Assess Health Care. 2007;23(2):286-291.

11. Yaxley JW, Coughlin GD, Chambers SK, et al. Robot-assisted laparoscopic prostatectomy versus open radical retropubic prostatectomy: early outcomes from a randomised controlled phase 3 study. Lancet. 2016;388(10049):1057-1066.

12. Wallis CJD, Detsky AS. Pitfalls of prioritizing cost-effectiveness in the assessment of medical innovation. Can Urol Assoc J. 2018;12(2):7-8.

13. Pound CR, Brawer MK, Partin AW. Evaluation and treatment of men with biochemical prostate-specific antigen recurrence following definitive therapy for clinically localized prostate cancer. Rev Urol. 2001;3(2):72-84.

14. Danielson B, Saad F, So A, et al. Management algorithms for prostate-specific antigen progression in prostate cancer: Biochemical recurrence after definitive therapy and progression to non-metastatic castrate-resistant prostate cancer. Can Urol Assoc J. 2019;13(12):420-426. 
15. Antonarakis ES, Feng Z, Trock BJ, et al. The natural history of metastatic progression in men with prostate-specific antigen recurrence after radical prostatectomy: long-term follow-up. BJU Int. 2012;109(1):32-39.

16. Carlin AM, Zeni TM, English WJ, et al. The comparative effectiveness of sleeve gastrectomy, gastric bypass, and adjustable gastric banding procedures for the treatment of morbid obesity. Ann Surg. 2013;257(5):791-797.

17. Crook JM, O'Callaghan CJ, Duncan G, et al. Intermittent androgen suppression for rising PSA level after radiotherapy. $N$ Engl J Med. 2012;367(10):895-903.

18. Dragomir A, Dinea D, Vanhuyse M, Cury FL, Aprikian AG. Drug costs in the management of metastatic castration-resistant prostate cancer in Canada. BMC Health Serv Res. 2014;14:252.

19. Klotz L, Zhang L, Lam A, Nam R, Mamedov A, Loblaw A. Clinical results of long-term follow-up of a large, active surveillance cohort with localized prostate cancer. J Clin Oncol. 2010;28(1):126-131.

20. Sanyal C, Aprikian A, Cury F, Chevalier S, Dragomir A. Clinical management and burden of prostate cancer: a Markov Monte Carlo model. PLoS One. 2014;9(12):e113432.

21. Seo HJ, Lee NR, Son SK, Kim DK, Rha KH, Lee SH. Comparison of Robot-Assisted Radical Prostatectomy and Open Radical Prostatectomy Outcomes: A Systematic Review and MetaAnalysis. Yonsei Med J. 2016;57(5):1165-1177.

22. Briggs A. CC, , and Mark Sculpher. Decision Modeling for Health Economic Evaluation. New York: Oxford University Press Inc.; 2006.

23. Life Tables in 2011 in Canada. http://www.mortality.org Published 2013. Accessed.

24. CADTH Guidelines for the Economic Evaluation of Health Technologies: Canada 4th Edition. 2017.

25. Krahn MD, Bremner KE, Alibhai SM, et al. A reference set of health utilities for long-term survivors of prostate cancer: population-based data from Ontario, Canada. Qual Life Res. 2013;22(10):2951-2962.

26. Pataky R, Gulati R, Etzioni R, et al. Is prostate cancer screening cost-effective? A microsimulation model of prostate-specific antigen-based screening for British Columbia, Canada. Int J Cancer. 2014;135(4):939-947.

27. McAlpine K, Forster AJ, Breau RH, et al. Robotic surgery improves transfusion rate and perioperative outcomes using a broad implementation process and multiple surgeon learning curves. Can Urol Assoc J. 2019;13(6):184-189.

28. Krahn MD, Bremner KE, Zagorski B, et al. Health care costs for state transition models in prostate cancer. Med Decis Making. 2014;34(3):366-378.

29. Nam RK, Herschorn S, Loblaw DA, et al. Population based study of long-term rates of surgery for urinary incontinence after radical prostatectomy for prostate cancer. J Urol. 2012;188(2):502-506.

30. Sheppard CE, Lester EL, Chuck AW, et al. Medical tourism and bariatric surgery: who pays? Surgical endoscopy. 2014;28(12):3329-3336.

31. Kim SC, Song C, Kim W, et al. Factors determining functional outcomes after radical prostatectomy: robot-assisted versus retropubic. Eur Urol. 2011;60(3):413-419. 
32. Nyberg M, Hugosson J, Wiklund P, et al. Functional and Oncologic Outcomes Between Open and Robotic Radical Prostatectomy at 24-month Follow-up in the Swedish LAPPRO Trial. Eur Urol Oncol. 2018;1(5):353-360.

33. Al-Shaiji TF, Kanaroglou N, Thom A, et al. A cost-analysis comparison of laparoscopic radical prostatectomy versus open radical prostatectomy: the McMaster Institute of Urology experience. Can Urol Assoc J. 2010;4(4):237-241.

34. Ontario Ministry of Health and Long Term Care. Schedule of Benefits, Physician Services Under the Health Insurance Act. 2000.

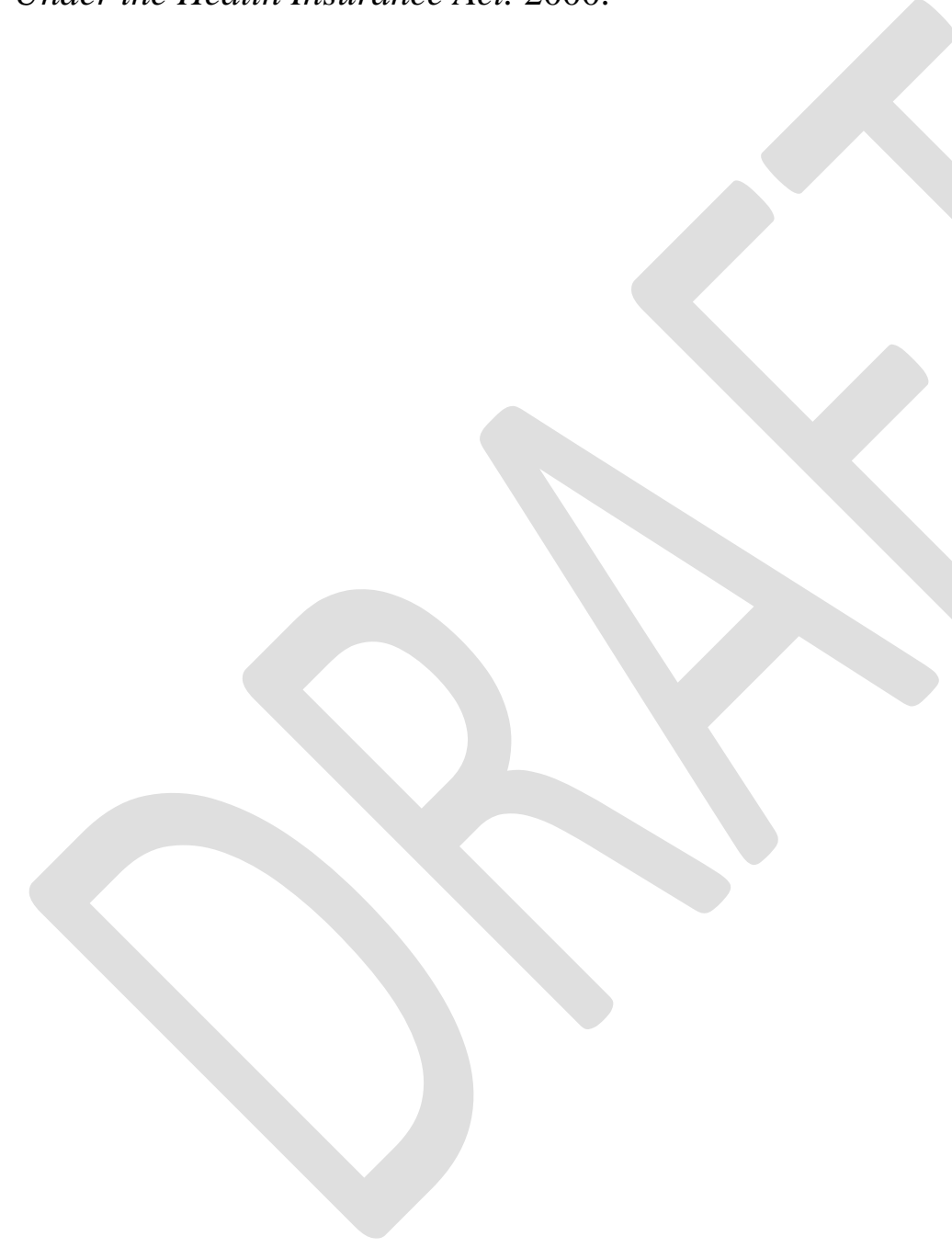




\section{Figures and Tables}

Fig. 1. Diagrammatic representation of the Markov model. States of the model is represented by the ovals, transition between states represented by the arrows.

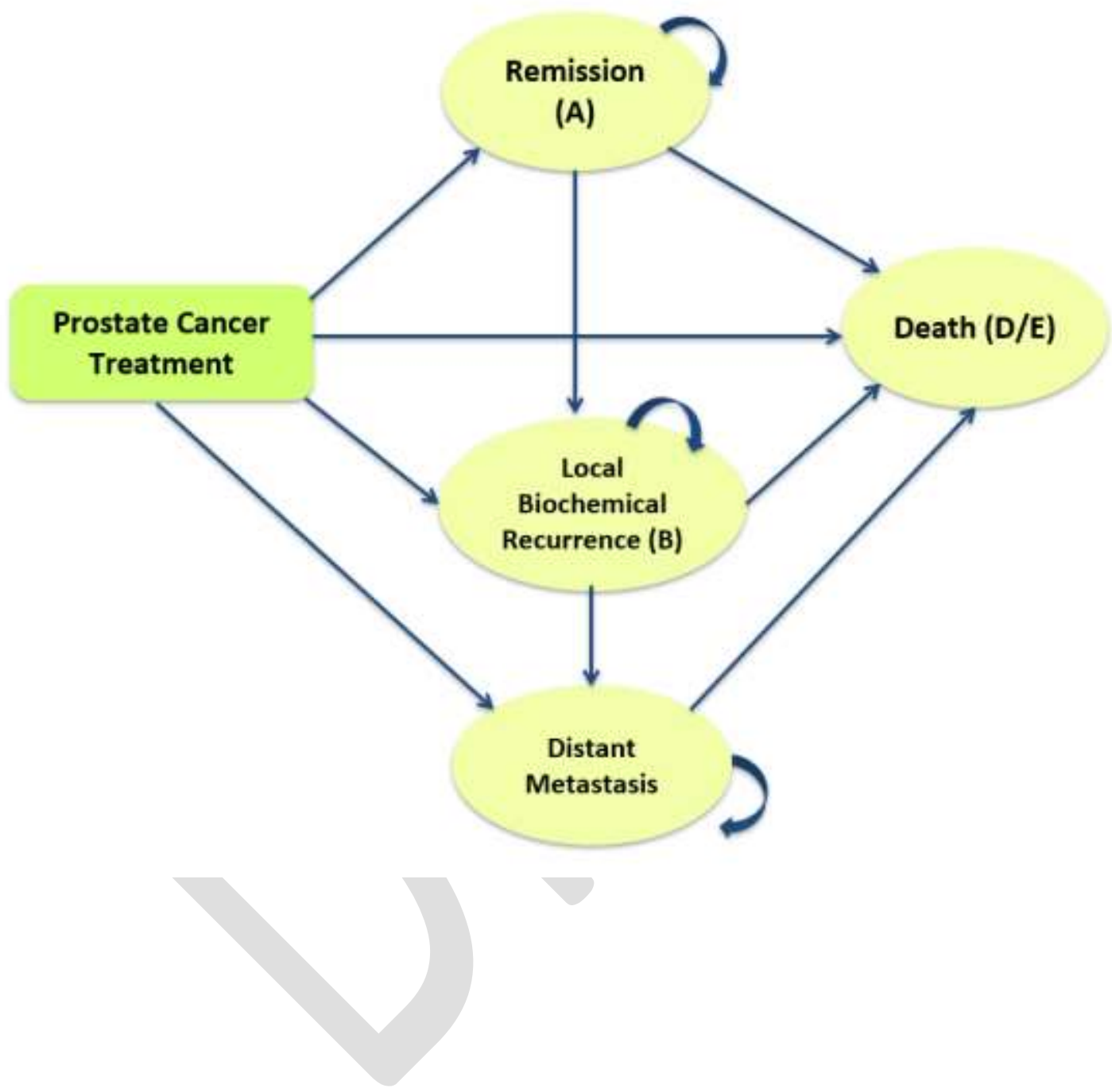


Fig. 2. Cost-effectiveness acceptability curve.

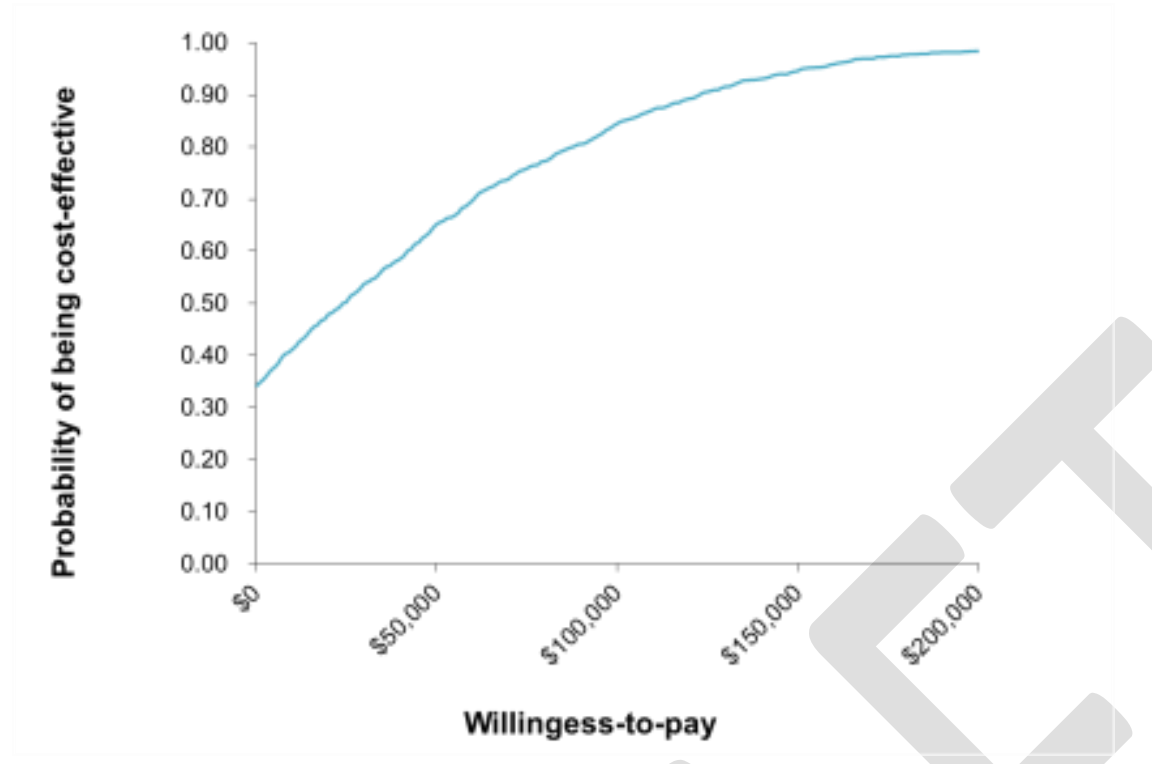

Fig. 3. Deterministic sensitivity analysis tornado diagram. Results of selective one-way sensitivity analysis in which several model input parameters were varied to determine their effect on the incremental cost-effectiveness ratio (ICER). Blue bars represent the base-case input parameter values minus $20 \%$, the red bars represent base case input parameter values plus $20 \%$. Urinary incontinence (UI) disutility was varied by $45 \%$ and utility of remission and recurrence were varied by $10 \%$, see methods for rationale. The horizontal axis represents ICERs. ED: erectile dysfunction.

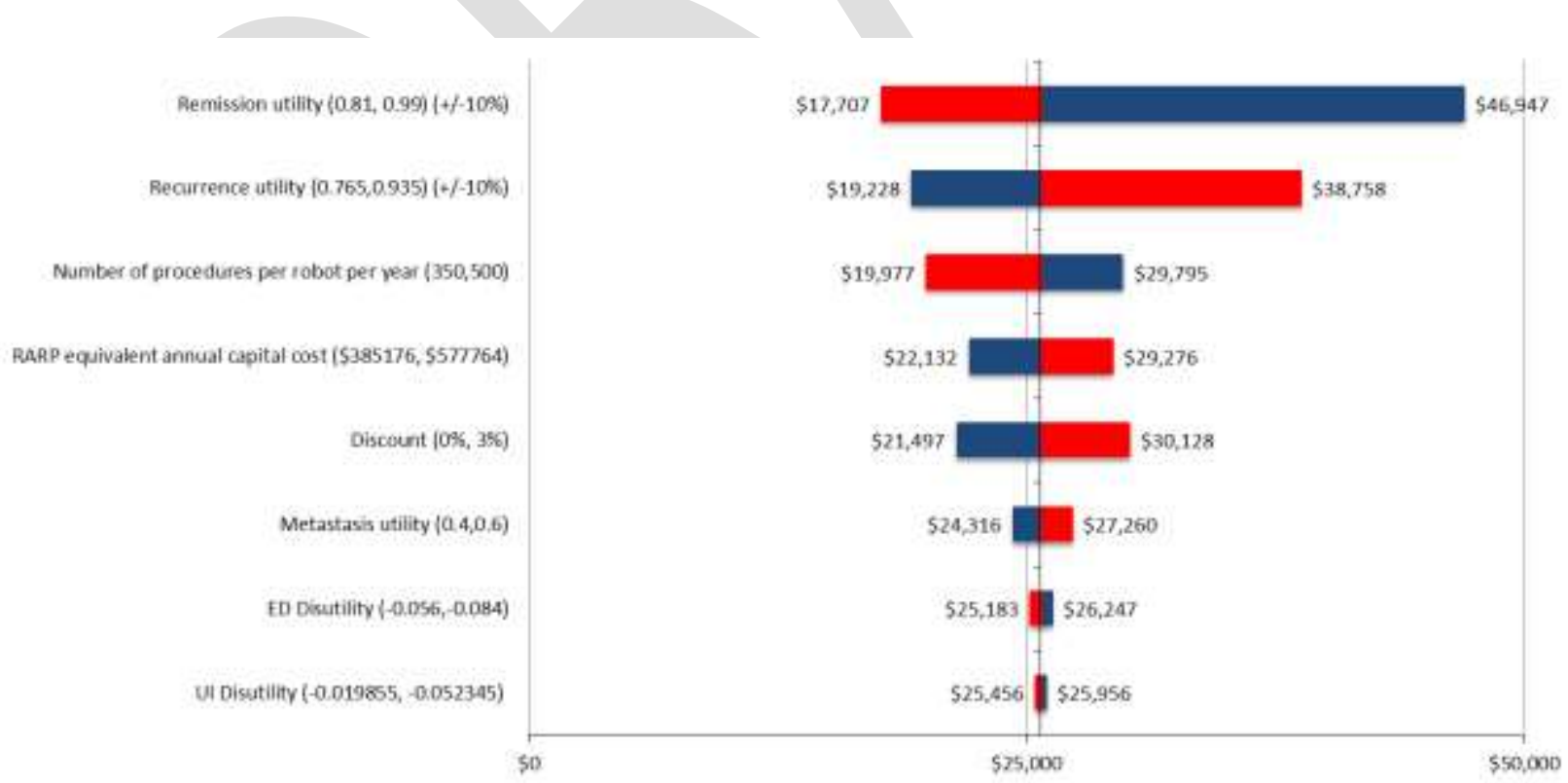




\begin{tabular}{|c|c|c|}
\hline Oncological outcomes & Input & References \\
\hline ORP to recurrence & 0.03 & Klotz et al, $2009^{19}$; Sanyal et al, $2014^{20}$ \\
\hline ORP to death & 0.02 & Statistics Canada ${ }^{23}$; Sanyal et al, $2014^{20}$ \\
\hline Recurrence to metastasis & 0.07 & Crook et al, 2012 $2^{17}$; Sanyal et al, $2014^{20}$ \\
\hline Recurrence to death & 0.03 & Statistics Canada $^{23} ;$ Sanyal et al, $2014^{20}$ \\
\hline Metastasis to death & 0.27 & Dragomir et al, $2014^{18}$; Sanyal et al, $2014^{20}$ \\
\hline $\begin{array}{l}\text { Risk ratio of recurrence, } \\
\text { RARP vs. ORP }\end{array}$ & $\begin{array}{c}0.71 \\
(0.61-0.81)\end{array}$ & Seo et al, $2016^{21}$ \\
\hline \multicolumn{3}{|l|}{ All-cause mortality } \\
\hline Age, years & Input & Reference $^{23}$ \\
\hline 60 & 0.00791 & Life table \\
\hline 61 & 0.00846 & Life table \\
\hline 62 & 0.00870 & Life table \\
\hline 63 & 0.00994 & Life table \\
\hline 64 & 0.01136 & Life table \\
\hline 65 & 0.01161 & Life table \\
\hline 66 & 0.01306 & Life table \\
\hline 67 & 0.01452 & Life table \\
\hline 68 & 0.01595 & Life table \\
\hline 69 & 0.01713 & Life table \\
\hline Functional outcomes & Input & Reference \\
\hline UI after ORP & 0.12 & Seo et al, $2016^{21}$ \\
\hline ED after ORP & 0.52 & Seo et al, $2016^{21}$ \\
\hline UI after RARP & 0.08 & Seo et al, $2016^{21}$ \\
\hline ED after RARP & 0.40 & Seo et al, $2016^{21}$ \\
\hline
\end{tabular}

ED: erectile dysfunction; ORP: open radical prostatectomy; RARP: robot-assisted radical prostatectomy; UI: urinary incontinence.

\begin{tabular}{|c|c|c|}
\hline Health state & Input & References \\
\hline Remission & 0.90 & Pataky $2014^{26}$ \\
\hline Local biochemical recurrence & 0.85 & Pataky $2014^{26}$ \\
\hline Metastasis & 0.50 & Pataky $2014^{26}$ \\
\hline Death & 0.00 & Pataky $2014^{26}$ \\
\hline Urinary incontinence & -0.0361 & Krahn et al, $2013^{25} ;$ HQO $2017^{5}$ \\
\hline Erectile dysfunction & -0.0568 & Krahn et al, $2013^{25}$; HQO $2017^{5}$ \\
\hline
\end{tabular}




\begin{tabular}{|c|c|c|c|c|c|}
\hline \multicolumn{6}{|c|}{ Table 3. Direct medical cost of RARP and ORP } \\
\hline \multirow[b]{2}{*}{ Healthcare resource } & \multirow[b]{2}{*}{$\begin{array}{c}\text { Unit price } \\
\text { (\$CAD) }\end{array}$} & \multicolumn{2}{|c|}{ RARP } & \multicolumn{2}{|c|}{ ORP } \\
\hline & & $\begin{array}{c}\text { Resource } \\
\text { utilization }\end{array}$ & $\begin{array}{c}\text { Cost } \\
(\$ C A D)\end{array}$ & $\begin{array}{c}\text { Resource } \\
\text { utilization }\end{array}$ & $\begin{array}{c}\text { Cost } \\
(\$ C A D)\end{array}$ \\
\hline $\begin{array}{l}\text { Robotic equipment \& } \\
\text { service fee }\end{array}$ & - & - & 1930 & - & - \\
\hline Disposables & - & - & 3611 & - & $284^{\mathrm{a}}$ \\
\hline Operating room & $1592 / \mathrm{hr}^{\mathrm{b}}$ & $4.60^{c}$ & 7323.20 & $4.46^{\mathrm{c}}$ & 7100.32 \\
\hline Recovery room & $150 / \mathrm{hr}^{\mathrm{b}}$ & $2.60^{\mathrm{c}}$ & 390 & $3.85^{\mathrm{c}}$ & 577.50 \\
\hline Hospital stay & $1400 /$ day $^{b}$ & $1.4^{\mathrm{c}}$ & 1960 & $2.8^{\mathrm{c}}$ & 3920 \\
\hline Surgeon fees & - & - & 1508 & - & $1081^{\mathrm{d}}$ \\
\hline Anesthesia & $15 /$ unit $^{\mathrm{d}}$ & $10^{\mathrm{d}}$ & 150 & $10^{\mathrm{d}}$ & 150 \\
\hline Blood transfusion & 238.24/unit ${ }^{\mathrm{e}}$ & $0.018^{\mathrm{c}}$ & 4.29 & $0.34^{\mathrm{c}}$ & 81.00 \\
\hline Readmission & $4917^{b}$ & $0.029^{c}$ & 142.59 & $0.034^{\mathrm{c}}$ & 167.18 \\
\hline Total avg costs & - & - & 17018.76 & - & 13361.00 \\
\hline
\end{tabular}

${ }^{\mathrm{a}} \mathrm{HQO}$ HTA ${ }^{5}$; ${ }^{\mathrm{b}}$ St. Joseph's Healthcare Hamilton (Ontario) Finance Department ${ }^{33}$; ${ }^{\mathrm{M}} \mathrm{McAlpine}$ et al,

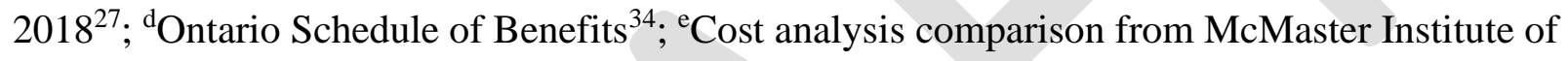
Urology $^{33}$.

\begin{tabular}{|l|c|c|c|}
\hline \multicolumn{3}{|c|}{ Table 4. Details of health state costs } & \multicolumn{3}{|c|}{ Health states } \\
\hline Healthcare resources & Remission & Progression & Metastasis \\
\hline Diagnostic tests & $\$ 257$ & $\$ 489$ & $\$ 1511$ \\
\hline Family practitioner visits & $\$ 211$ & $\$ 257$ & $\$ 392$ \\
\hline Specialist visits & $\$ 262$ & $\$ 456$ & $\$ 857$ \\
\hline $\begin{array}{l}\text { Non-diagnostic medical procedures, allied } \\
\text { Healthcare, and miscellaneous }\end{array}$ & $\$ 430$ & $\$ 802$ & $\$ 1705$ \\
\hline Inpatient stays & $\$ 806$ & $\$ 2688$ & $\$ 5629$ \\
\hline Same-day surgery & $\$ 266$ & $\$ 536$ & $\$ 1008$ \\
\hline Emergency room visits & $\$ 59$ & $\$ 114$ & $\$ 169$ \\
\hline Outpatient medications & $\$ 772$ & $\$ 2485$ & $\$ 5359$ \\
\hline Homecare/complex care/long-term care & $\$ 4$ & $\$ 25$ & $\$ 435$ \\
\hline Radiation therapy & $\$ 17$ & $\$ 241$ & $\$ 232$ \\
\hline Total annual health state costs & $\$ 3084$ & $\$ 8093$ & $\$ 17296$ \\
\hline
\end{tabular}




\begin{tabular}{|l|c|c|c|c|c|}
\hline \multicolumn{6}{|l|}{ Table 5. Base case cost-effectiveness results over 10 years } \\
\hline $\begin{array}{l}\text { Radical } \\
\text { prostatectomy }\end{array}$ & $\begin{array}{c}\text { Expected } \\
\text { cost }\end{array}$ & $\begin{array}{c}\Delta \text { Expected } \\
\text { costs }\end{array}$ & Expected QALYs & $\begin{array}{c}\Delta \text { Expected } \\
\text { QALYs }\end{array}$ & ICER \\
\cline { 1 - 1 } RARP & $\$ 47033$ & \multirow{2}{*}{$\$ 1701$} & 7.2047 & \multirow{2}{*}{0.0662} & $\begin{array}{c}\$ 25704 \\
\text { per QALY }\end{array}$ \\
\hline ORP & $\$ 45332$ & & 7.1385 & &
\end{tabular}

ICER: incremental cost-effectiveness ratio; ORP: open radical prostatectomy; QALY: qualityadjusted life years; RARP: robot-assisted radical prostatectomy. 


\section{APPENDICES}

Appendix A: Economic Evaluations of Robot-Assisted Radical Prostatectomy

Table 1: Comparison of RARP Economic Evaluations conducted to date

\begin{tabular}{|c|c|c|c|c|c|c|}
\hline & Alberta $^{6}$ & $\mathrm{HQO}^{5}$ & Denmark $^{9}$ & Ireland $^{7}$ & Australia ${ }^{10}$ & $\mathbf{U S}^{8}$ \\
\hline Year & 2017 & 2017 & 2011 & 2011 & 2007 & 2013 \\
\hline Population & $\begin{array}{l}\text { Patients } \\
\text { with } \\
\text { localized } \\
\text { prostate } \\
\text { cancer } \\
\text { (mean } \\
\text { age=60 } \\
\text { years) }\end{array}$ & $\begin{array}{l}\text { Patients } \\
\text { with } \\
\text { localized } \\
\text { prostate } \\
\text { cancer } \\
\text { (mean age } \\
=60 \text { years) }\end{array}$ & $\begin{array}{l}\text { Patients } \\
\text { with } \\
\text { localized } \\
\text { prostate } \\
\text { cancer } \\
\text { (age 50- } \\
69 \text { ) }\end{array}$ & $\begin{array}{l}\text { Patients } \\
\text { with } \\
\text { prostate } \\
\text { cancer } \\
\text { (median age } \\
=58 \text { ) }\end{array}$ & $\begin{array}{l}\text { Patients } \\
\text { with } \\
\text { prostate } \\
\text { cancer }\end{array}$ & $\begin{array}{l}\text { Patients } \\
\text { with } \\
\text { localized } \\
\text { prostate } \\
\text { cancer } \\
\text { (mean age } \\
=65 \text { ) }\end{array}$ \\
\hline Intervention & $\begin{array}{l}\text { Robot } \\
\text { assisted } \\
\text { radical } \\
\text { prostatecto } \\
\text { my (RARP) }\end{array}$ & RARP & $\mathrm{RA}$ & RARP & RARP & RARP \\
\hline Comparator & $\begin{array}{l}\text { Open } \\
\text { radical } \\
\text { prostatecto } \\
\text { my (ORP), } \\
\text { laparoscopic } \\
\text { radical } \\
\text { prostatecto } \\
\text { my (LRP), } \\
\text { external } \\
\text { beam } \\
\text { radiotherapy } \\
\text { (RT), } \\
\text { brachythera } \\
\text { py (BT) and } \\
\text { cryoablation }\end{array}$ & ORP & ORP & ORP & ORP & ORP \\
\hline $\begin{array}{l}\text { Time } \\
\text { Horizon }\end{array}$ & 9 year & 1 year & 1 year & 7 years & Not stated & Lifetime \\
\hline
\end{tabular}




\begin{tabular}{|c|c|c|c|c|c|c|}
\hline Perspective & Payer & Payer & $\begin{array}{l}\text { Payer \& } \\
\text { Societal }\end{array}$ & Payer & Payer & Payer \\
\hline $\begin{array}{l}\text { Type of } \\
\text { Analysis }\end{array}$ & CUA & CUA & CEA & CUA & CUA & CUA \\
\hline Model type & $\begin{array}{l}\text { Markov } \\
\text { Model }\end{array}$ & $\begin{array}{l}\text { Markov } \\
\text { Model }\end{array}$ & $\begin{array}{l}\text { Cohort- } \\
\text { based }\end{array}$ & $\begin{array}{l}\text { Markov } \\
\text { Model }\end{array}$ & $\begin{array}{l}\text { Decision } \\
\text { Tree }\end{array}$ & $\begin{array}{l}\text { Markov } \\
\text { Model }\end{array}$ \\
\hline Structure & $\begin{array}{l}\text { Semi-annual } \\
\text { cycles }\end{array}$ & $\begin{array}{l}\text { Yearly } \\
\text { cycles }\end{array}$ & N/A & $\begin{array}{l}\text { Yearly } \\
\text { cycles }\end{array}$ & $\begin{array}{l}\text { Yearly } \\
\text { cycles }\end{array}$ & Monthly \\
\hline \multicolumn{7}{|l|}{ Health States } \\
\hline $\begin{array}{l}\text { No evidence } \\
\text { of diseases } \\
\text { (NED) }\end{array}$ & $\checkmark$ & $\checkmark$ & $\checkmark$ & $\checkmark$ & $\checkmark$ & $\checkmark$ \\
\hline $\begin{array}{l}\text { Biochemical } \\
\text { (PSA) } \\
\text { recurrence } \\
(\text { BCR })\end{array}$ & $\checkmark$ & $\checkmark$ & $\checkmark$ & & $\checkmark$ & $\checkmark$ \\
\hline $\begin{array}{l}\text { Positive } \\
\text { surgical } \\
\text { margin status }\end{array}$ & $\checkmark$ & & & & $\checkmark$ & \\
\hline $\begin{array}{l}\text { Distant } \\
\text { metastasis } \\
\text { (DM) }\end{array}$ & $\checkmark$ & $\checkmark$ & & & & $\checkmark$ \\
\hline Death & $\checkmark$ & $\checkmark$ & 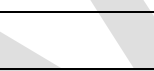 & $\checkmark$ & & $\checkmark$ \\
\hline \multicolumn{7}{|c|}{$\begin{array}{l}\text { Functional } \\
\text { Outcomes/AE } \\
\text { s }\end{array}$} \\
\hline Blood loss & $\checkmark$ & & & & $\checkmark$ & \\
\hline \multicolumn{7}{|l|}{$\begin{array}{l}\text { Bladder neck } \\
\text { contracture } \\
\text { (BNC) }\end{array}$} \\
\hline $\begin{array}{l}\text { Urinary } \\
\text { incontinence } \\
\text { (UI) }\end{array}$ & $\checkmark$ & $\checkmark$ & $\checkmark$ & $\checkmark$ & $\checkmark$ & $\checkmark$ \\
\hline $\begin{array}{l}\text { Erectile } \\
\text { dysfunction } \\
\text { (ED) }\end{array}$ & $\checkmark$ & $\checkmark$ & $\checkmark$ & $\checkmark$ & $\checkmark$ & $\checkmark$ \\
\hline
\end{tabular}




\begin{tabular}{|c|c|c|c|c|c|c|}
\hline $\begin{array}{l}\text { Urinary tract } \\
\text { infection } \\
\text { (UTI) }\end{array}$ & $\checkmark$ & & & & & \\
\hline Pain & $\checkmark$ & $\checkmark$ & & & $\checkmark$ & \\
\hline $\begin{array}{l}\text { Source of } \\
\text { Clinical Data }\end{array}$ & $\begin{array}{l}\text { AHS Meta- } \\
\text { analysis, } \\
\text { Edmonton } \\
\text { Prostatecto } \\
\text { my } \\
\text { Registry, } \\
\text { Horwitz } \\
2005, \\
\text { LifeTables_ } \\
\text { AB }\end{array}$ & $\begin{array}{l}1 \text { RCT } \\
\text { (Yaxley } \\
2016 \text { ), } \\
\text { Sanyal } \\
2014, \\
\text { LifeTable, } \\
\text { Nam 2012, } \\
\text { Kim 2011, } \\
\text { Seo } 2016\end{array}$ & $\begin{array}{l}\text { Cohort } \\
\text { study } \\
\text { (Hospital } \\
\text { data, } \\
\text { Registry } \\
\text { etc) }\end{array}$ & $\begin{array}{l}\text { Meta- } \\
\text { analysis }\end{array}$ & $\begin{array}{l}\text { Menon } \\
2005\end{array}$ & $\begin{array}{l}\text { Literature } \\
\text { review \& } \\
\text { Expert } \\
\text { panel }\end{array}$ \\
\hline $\begin{array}{l}\text { Source of } \\
\text { Utility }\end{array}$ & $\begin{array}{l}\text { Yaxley } \\
2016, \text { Krahn } \\
2009, \\
\text { Cooperberg } \\
2012, \text { Volk } \\
2004, \\
\text { Shimizu } \\
2008\end{array}$ & $\begin{array}{l}\text { Some } \\
\text { calculated, } \\
\text { Krahn } \\
2009 \text {, Naik } \\
2015\end{array}$ & $\begin{array}{l}\text { Cohort } \\
\text { study } \\
\text { (Hospital } \\
\text { data) }\end{array}$ & $\begin{array}{l}\text { Sommers } \\
2007 \text {, } \\
\text { Stewart } \\
2005\end{array}$ & $\begin{array}{l}\text { Menon } \\
2005\end{array}$ & $\begin{array}{l}\text { Literature } \\
\text { review \& } \\
\text { Cost- } \\
\text { Effectiven } \\
\text { ess } \\
\text { Analysis } \\
\text { Registry }\end{array}$ \\
\hline \multicolumn{7}{|l|}{ Cost Inputs } \\
\hline $\begin{array}{l}\text { Length of } \\
\text { stay }\end{array}$ & & & & $\checkmark$ & $\checkmark$ & $\checkmark$ \\
\hline $\begin{array}{l}\text { Operative } \\
\text { time }\end{array}$ & & $\checkmark$ & & & $\checkmark$ & $\checkmark$ \\
\hline $\begin{array}{l}\mathrm{AE} \\
\text { associated } \\
\text { treatment }\end{array}$ & & $\checkmark$ & $\checkmark$ & $\checkmark$ & $\checkmark$ & $\checkmark$ \\
\hline Procedure & $\checkmark$ & $\checkmark$ & $\checkmark$ & $\checkmark$ & $\checkmark$ & $\checkmark$ \\
\hline $\begin{array}{l}\text { Overhead/ca } \\
\text { pital cost }\end{array}$ & $\checkmark$ & $\checkmark$ & $\checkmark$ & $\checkmark$ & $\checkmark$ & \\
\hline $\begin{array}{l}\text { Blood } \\
\text { transfusion } \\
\text { rate }\end{array}$ & & $\checkmark$ & $\checkmark$ & $\checkmark$ & & \\
\hline
\end{tabular}




\begin{tabular}{|c|c|c|c|c|c|c|}
\hline $\begin{array}{l}\text { Readmission } \\
\text { rate }\end{array}$ & & $\checkmark$ & $\checkmark$ & & & \\
\hline $\begin{array}{l}\text { Source of } \\
\text { Costs }\end{array}$ & $\begin{array}{l}\text { Alberta } \\
\text { Health } \\
\text { Administrati } \\
\text { ve data }\end{array}$ & $\begin{array}{l}\text { Experts, } \\
\text { Yaxley } \\
2016, \\
\text { Ontario } \\
\text { Schedule } \\
\text { of } \\
\text { Benefits, } \\
\text { Provincial } \\
\text { costing } \\
\text { studies }\end{array}$ & $\begin{array}{l}\text { Cohort } \\
\text { study } \\
\text { (Hospital } \\
\text { fee } \\
\text { schedule) } \\
\text { \& other } \\
\text { literature }\end{array}$ & $\begin{array}{l}\text { Department } \\
\text { of Health }\end{array}$ & $\begin{array}{l}\text { MSCC, } \\
\text { MSAC, } \\
\text { Administrati } \\
\text { ve database }\end{array}$ & $\begin{array}{l}\text { Medicare } \\
\text { Fee-for- } \\
\text { service \& } \\
\text { Medicare } \\
\text { Fee } \\
\text { Schedules }\end{array}$ \\
\hline ICER & $\begin{array}{l}\$ 44,471 / \mathrm{QA} \\
\mathrm{LY}(\mathrm{CAD})\end{array}$ & $\begin{array}{l}\$ 5.2 \mathrm{M} / \mathrm{QA} \\
\mathrm{LY}(\mathrm{CAD})\end{array}$ & $\begin{array}{l}€ 64,343 / \mathrm{e} \\
\text { xtra } \\
\text { successful } \\
\text { treatment }\end{array}$ & $\begin{array}{l}€ 26,647 / \mathrm{QA} \\
\mathrm{LY}\end{array}$ & $\begin{array}{l}\$ 24,457 / \mathrm{QA} \\
\text { LY (AUD) }\end{array}$ & $\begin{array}{l}\text { ICER not } \\
\text { calculated }\end{array}$ \\
\hline
\end{tabular}

